\title{
Reduced survival after autologous stem cell transplantation in myeloma and lymphoma patients with low vitamin D serum levels.
}

\author{
Original article
}

Authors: Florian Eicher ${ }^{1}$, Behrouz Mansouri Taleghani ${ }^{2}$, Christof Schild $^{3}$, Ulrike Bacher ${ }^{2}$, Thomas Pabst ${ }^{1}$

Affiliations: ${ }^{1}$ Department of Medical Oncology; ${ }^{2}$ Department of Hematology; ${ }^{3}$ Department of Clinical Chemistry; Inselspital, University Hospital Bern, University of Bern, Bern, Switzerland.

Manuscript details: Manuscript: 2292 words; abstract: 194 words; 44 references; 3 tables; 1 figure.

Key words: Vitamin D; deficiency; autologous stem cell transplantation (ASCT); lymphoma; multiple myeloma; prognosis.

Running title: Vitamin D levels affect outcome after ASCT.

Corresponding author: Thomas Pabst, MD; Extraordinary Professor; Department of Medical Oncology; University Hospital; 3010 Berne; Switzerland. Tel.: +41 31632 8430; fax: +41 31 632 3410. E-mail: thomas.pabst@insel.ch

This article has been accepted for publication and undergone full peer review but has not been through the copyediting, typesetting, pagination and proofreading process which may lead to differences between this version and the Version of Record. Please cite this article as doi: 10.1002/hon. 2774 


\begin{abstract}
High-dose chemotherapy (HDCT) with autologous stem cell transplantation (ASCT) is applied for consolidation in myeloma and relapsing lymphoma patients. Vitamin D (VitD) exerts effects during hematopoietic stem cell proliferation, differentiation and interactions with the immune system. VitD deficiency is frequent in patients with hematological malignancies, but its prognostic relevance after ASCT remains unclear. We investigated the effect of VitD serum levels in patients with lymphomas and myeloma at ASCT on progression-free (PFS) and overall survival (OS). The cohort $(n=183)$ was divided in two groups: $81(44 \%)$ had VitD levels $>52 \mathrm{nmol} / \mathrm{L}$ and $102(56 \%) \leq 52 \mathrm{nmol} / \mathrm{L}$ at ASCT. VitD levels $>52 \mathrm{nmol} / \mathrm{L}$ were associated with better PFS ( $p=0.0194)$ and OS ( $p=0.011)$. Similarly, when evaluating myeloma patients alone, patients with lower VitD levels ( $\leq 52 \mathrm{nmol} / \mathrm{L})$ had inferior PFS $(p=0.0412)$ and $\mathrm{OS}(p=0.049)$. Finally, the multivariate analysis was consistent that varying VitD levels were significantly associated with OS $(p=0.0167)$, also when stratifying patients in groups with VitD levels > versus $\leq 52 \mathrm{nmol} / \mathrm{L}(\mathrm{p}=0.0421)$. Our data suggest that reduced serum VitD levels in myeloma and lymphoma patients undergoing HDCT/ASCT are associated with inferior outcome. Optimizing VitD levels before ASCT may be warranted.
\end{abstract}




\section{Introduction}

High-dose chemotherapy (HDCT) followed by autologous stem cell transplantation (ASCT) is a frequent consolidation option for patients with various hematological malignancies ${ }^{1}$ including multiple myeloma (MM) and various lymphoma subtypes. A variety of factors were shown to be prognostically relevant for patients undergoing HDCT/ASCT, such as age, disease stage, presence of B-symptoms or extranodal manifestations, ${ }^{2,3}$ whereas the role of Vitamin D (VitD) serum levels is unclear in this setting.

VitD is a fat-soluble vitamin, vastly acquired by endogenous production mediated following UVB radiation, which is highly relevant for regulation of calcium and phosphate homeostasis. 25-hydroxyvitamin D3 is the main circulating metabolite and total 25-hydroxyvitamin D (25$\mathrm{OH}-\mathrm{D}$ ) reflects the VitD status. ${ }^{4}$ The biologically active form 1,25-hydroxy-VitD acts on the nuclear VitD receptor (VDR) and promotes intestinal calcium and phosphate absorption. VDRs are not only expressed in tissues involved in calcium homeostasis, but in many other tissues and cell types. ${ }^{4}$ There is growing evidence that vitamin D signaling is not restricted to cells involved in calcium homeostasis, but rather affect a variety of cellular processes such as proliferation, apoptosis, differentiation, angiogenesis and metastasis. ${ }^{4-10}$ Moreover, VitD metabolites were documented to exert various modulatory effects on the immune system. ${ }^{11}$ Such pathways may also be of significance during and after HDCT with ASCT, even more so as VitD deficiency is frequent in the general population, ${ }^{12}$ and even more so in patients with hematological malignancies. In various studies, in between $30 \%$ and $80 \%$ of patients with different hematological malignancies and within different treatment settings were reported to show VitD serum levels less than $50 \mathrm{nmol} / \mathrm{L},{ }^{13-16}$ and around $50 \%$ of patients were reported to show serum levels less than $30 \mathrm{nmol} / \mathrm{L} .{ }^{17}$ In addition, there is an ongoing debate on the ideal 
threshold to define VitD deficiency, which is reflected by varying cutoffs among different studies.

In solid tumors, the role of VitD has been extensively explored particularly with regards to its potential anti-cancer effects suggesting that VitD may inhibit carcinogenesis and can be associated with superior outcome in various solid tumors such as colorectal, ${ }^{18-20}$ prostate, ${ }^{21,22}$ breast, ${ }^{23-25}$ bladder, ${ }^{26}$ ovarian, ${ }^{27,28}$ lung,${ }^{29,30}$ and thyroid cancer ${ }^{31}$. In patients with hematological malignancies, higher VitD levels were reported to be associated with superior outcomes. ${ }^{13,15-}$ 17,32-35 However, these studies were limited to patients undergoing allogeneic hematopoietic stem cell transplantation, and literature on VitD in the autologous transplant setting is scarce. ${ }^{6,36}$ Thus, the prognostic value of pre-transplant VitD levels has not been thoroughly investigated in the HDCT/ASCT setting in patients with hematological malignancies. In this study, we evaluated the effect of varying $25-\mathrm{OH}$-VitD levels at the time of ASCT on the clinical outcome in patients with multiple myeloma and various lymphomas.

\section{Material and Methods}

\section{Patients and study design}

We analyzed all adult patients ( $\geq 18$ years) with multiple myeloma and various lymphoma subtypes undergoing HDCT with ASCT between 03/2012 and 07/2018 at the University Hospital of Bern, Switzerland. Availability of vitamin D assessment on the day of hospital admission for high-dose chemotherapy (HDCT) before the ASCT was required for inclusion in the study. In patients with tandem transplantation procedures, the first ASCT was considered. Among the various VitD metabolites, only $25-\mathrm{OH}-\mathrm{VitD}$ was investigated as it primarily represents the VitD status and it is the predominant circulating metabolite. We collected data on clinical characteristics at diagnosis, treatment before ASCT, parameters related to 
HDCT/ASCT and clinical outcomes. The local ethics committee of Bern, Switzerland, approved the study (decision number \# 374/15). All patients gave written informed consent.

\section{Methods and definitions}

The cohort was subdivided into two groups depending on the $25-\mathrm{OH}-\mathrm{VitD}$ serum levels. This resulted in one group with 25-OH-VitD levels above $52 \mathrm{nmol} / \mathrm{L}$ ("normal VitD") and a second group with $25-\mathrm{OH}-\mathrm{VitD} \leq 52 \mathrm{nmol} / \mathrm{L}$ ("low VitD"). This cut-off was based on the Endocrine Society guidelines of defining VitD deficiency as $<50 \mathrm{nmol} / \mathrm{L}$, and VitD insufficiency as 52.5 $72.5 \mathrm{nmol} / \mathrm{L} .{ }^{37}$ In accordance, this study investigated the impact of the pre-defined cut-off of $52 \mathrm{nmol} / \mathrm{L}$ on survival rates after HDCT/ASCT.

VitD was measured using the Liaison 25 Dihydroxyvitamin D total assay (DiaSorin, Stillwater, MN, USA). This assay is measuring total VitD (25-OH-VitD3 plus 25-OH-VitD2) as recommended by the Institute of Medicine 2011 guidelines. ${ }^{45}$

\section{Statistical analysis}

Primary endpoints of this study were PFS and OS of patients with VitD levels at HDCT/ASCT above versus below $52 \mathrm{nmol} / \mathrm{L}$, and survival rates were calculated using the method of Kaplan and Meier. Log-rank test was performed in order to compare survival proportions and calculate p-values. Unpaired t-test was applied for the comparison of medians and continuous variables between the two groups. Categorical clinical characteristics were compared using Fisher's exact test. The correlation of two variables was assessed using multivariable cox regression in the multivariate analysis, where the impact on PFS and OS of predictors such as VitD levels, gender, diagnosis, age, and remission status was assessed. P-values of less than 0.05 were considered to be significant. We calculated medians and totals by Microsoft Excel 2016 . 
GraphPad Prism 8 (GraphPad Software, La Jolla, CA) was applied to visualize Kaplan Meier curves and calculate all p-values (Log-rank test, unpaired t-test, Fisher's exact test).

\section{Results}

\section{Clinical characteristics}

During the study period, we identified 183 lymphoma and myeloma patients fulfilling the inclusion criteria. Within this cohort, 81 patients (44\%) had 25-OH-VitD levels above $52 \mathrm{nmol} / \mathrm{L}$ ("normal VitD"), and 102 patients (56\%) had VitD levels $\leq 52$ nmol/L ("low VitD"). The clinical characteristics of both groups are summarized in Table 1. There was a male preponderance ( $70 \%$ of patients) within the entire cohort, with the proportion of males being even higher in the low VitD group as compared to the normal VitD group ( $77 \%$ versus $62 \%$; $p=0.0356)$. Probably due to this gender imbalance in both groups, the body weight was lower in the normal VitD group (median $70 \mathrm{~kg}$ versus $77 \mathrm{~kg} ; \mathrm{p}=0.0098$ ). Whereas the proportion of patients in $\mathrm{CR}$ at the time of ASCT was comparable in the normal versus low VitD groups ( $16 \%$ vs. $23 \% ; p=0.3497$ ), more patients in the normal VitD group had PR (56\% vs. 38\%; $p=0.025)$ and less patients had progressive disease (PD; 4\% vs. 16\%; $p=0.0129$ ). Otherwise, both groups were comparable for clinical characteristics at diagnosis and for disease subtypes and stage distribution.

\section{Chemotherapy regimens and transplant details}

The regimens used for induction and high-dose chemotherapy (HDCT) are given in Table 2. We found no differences between the normal and the low VitD groups concerning the various chemotherapeutic regimens. Induction regimens in myeloma patients were bortezomib-based (VRD with bortezomib, lenalidomide, dexamethasone, or VCD with bortezomib, cyclophosphamide, dexamethasone), whereas HDCT was melphalan-based. Lymphoma 
patients predominantly received HDCT with $\mathrm{B}(\mathrm{e}) \mathrm{EAM}$ (bendamustine or BCNU, etoposide, cytarabine, melphalan). Furthermore, total numbers of transplanted CD34+ cells, intervals between ASCT and neutrophil recovery $>0.5 \mathrm{G} / \mathrm{L}$, and platelet recovery $>20 \mathrm{G} / \mathrm{L}$ were comparable between both groups (Table 2).

\section{Survival outcomes}

The overall mortality was lower in the normal VitD group as compared to the low VitD group (14\% versus $28 \% ; p=0.0191)$. Mortality in the first two years was $10 \%$ in the normal VitD and $25 \%$ in the low VitD group $(p=0.0075)$.

Figure 1 compares the survival outcomes of patients in the normal VitD ( $>52 \mathrm{nmol} / \mathrm{L}$ ) group to those in the low VitD $(\leq 52 \mathrm{nmol} / \mathrm{L})$ group. The PFS was superior in the normal VitD group as compared to the low VitD group (median 19.3 months versus 14.3 months; $p=0.0194$ ). When the lymphoma patients were separately analyzed, PFS did not differ significantly between patients with normal and low VitD levels $(p=0.251)$. In the myeloma patients, however, the PFS was longer in the normal VitD patients as compared to the low VitD patients (median 19.5 months versus 16.0 months; $p=0.0412$.

OS was superior in the normal VitD group (median 21.3 months versus 17.1 months; $p=0.011$ ). Again, OS did not differ significantly between normal and low VitD patients with lymphomas $(p=0.1242)$, whereas significant differences were documented in the myeloma patients: Median OS was 21.4 months in patients with normal VitD as compared to 20.4 months in patients with low VitD $(p=0.049)$.

\section{Prognostic parameters}


We investigated whether low VitD levels at the time of ASCT had an independent prognostic impact in a multivariate analysis depicted in Table 3. Other parameters in the multivariate analysis were patients' age at the time of ASCT (as continuous parameter), gender, disease, and remission status at the time of ASCT.

First, considering 25-OH-VitD levels as continuous variables, VitD levels were demonstrated to have an independent prognostic impact on overall survival $(p=0.0167)$. With the increase of the VitD level by one unit $(\mathrm{nmol} / \mathrm{L})$, the risk of death was reduced by $2 \%(\mathrm{HR}=0.98)$. Remarkably, none of the other variables included in the multivariate analysis was significantly associated with OS.

Secondly, we stratified patients into the two groups with normal versus low VitD levels considering the above cut-off of $52 \mathrm{nmol} / \mathrm{L}$. Again, this cut-off of VitD was the only parameter independently associated with OS $(p=0.0427)$. The hazard ratio for death was 0.51 in patients with VitD levels above $52 \mathrm{nmol} / \mathrm{L}$ compared to patients with VitD levels below this cutoff.

\section{Discussion}

In patients with hematological malignancies undergoing hematopoietic stem cell transplantation, higher VitD levels were reported to be associated with superior outcomes. ${ }^{13,15-}$ 17,32-35 However, these studies were limited to patients undergoing allogeneic stem cell transplantation, and literature on VitD in ASCT is scarce.$^{6,36}$ Thus, the prognostic value of pretransplant VitD levels has not been thoroughly investigated in in patients with hematological malignancies in the HDCT/ASCT setting, although HDCT/ASCT is a frequent consolidation option for patients with various hematological malignancies ${ }^{1}$ including myeloma and various lymphoma subtypes. 
Thus, we prospectively determined VitD levels in a large cohort of 183 patients with myeloma and lymphoma before HDCT/ASCT and investigated the effect of VitD serum levels on the survival outcomes. In accordance with Endocrine Society guidelines, which defined VitD deficiency as $<50 \mathrm{nmol} / \mathrm{L}$ and VitD insufficiency as $52.5-72.5 \mathrm{nmol} / \mathrm{L},{ }^{37}$ we applied a serum level of $52 \mathrm{nmol} / \mathrm{L}$ as threshold for our study.

First, in accordance with previous studies clearly showing that VitD deficiency is common among patients with hematological malignancies, ${ }^{13-17,32-35}$ we found reduced $25-\mathrm{OH}-\mathrm{D}$ levels $\leq 52 \mathrm{nmol} / \mathrm{L}$ in $56 \%$ of the patients in our cohort. Second, and even more important, we could clearly demonstrate that patients with reduced levels of VitD ( $\leq 52 \mathrm{nmol} / \mathrm{L})$ had inferior PFS (median 14.3 months versus 19.3 months; $\mathrm{p}=0.0194$ ) and OS group (median 17.1 months versus 21.3 months; $p=0.011$ ) as compared to patients with normal VitD levels (above the respective threshold). Moreover, we found a reduced VitD level to represent an independent negative prognostic parameter by multivariate analysis, whereas other parameters such as patients' age at the time of ASCT, gender, disease (myeloma versus lymphoma), and remission status at the time of ASCT had no independent prognostic impact.

"Sufficient" VitD levels have been associated with superior PFS and OS in patients with various solid tumors (colorectal, ${ }^{18-20}$ prostate, ${ }^{21,22}$ breast, ${ }^{23-25}$ bladder, ${ }^{26}$ ovarian, ${ }^{27,28}$ lung,,${ }^{29,30}$ thyroid cancer) $^{31}$ and hematological malignancies ${ }^{13,15-17,32-35}$ in previous reports. Nevertheless, VitD serum level is a general and unspecific marker indicating overall health and nutritional status, and VitD deficiency has been associated with inferior OS also in the general population. ${ }^{38}$ VitD levels were also reported to be prognostically relevant for the outcomes after allogeneic hematopoietic stem cell transplantation in patients with various hematological malignancies. $4,5,13,14,39,40$ The results of our study in accordance with a limited number of 
previous studies by others referring to $\mathrm{ASCT}^{6,36}$ suggest that the prognostic value of VitD levels is also operational in patients undergoing HDCT/ASCT.

In our study, the benefit of normal VitD levels was more evident in myeloma than in lymphoma patients. This may be due to the fact that HDCT/ASCT is a standard consolidation for myeloma patients as part of first-line treatment, whereas its role for lymphoma patients is more heterogeneous.

The role of VitD metabolites for immune system modulation and hematopoietic cell differentiation is well established:4-11 The VitD-receptor (VDR) is expressed on various precursor cells in the hematopoietic system. VDR-mediated effects include promotion of differentiation, apoptosis and growth inhibition, which are also involved during the development of hematological malignancies. Accordingly, low VitD levels have been associated with greater clonal proliferation in leukemic cells. ${ }^{33}$ VDR activation can also trigger differentiation and thereby enhance the numbers of mature cells. ${ }^{4,7}$ Thus, VRD-mediated mechanisms may also contribute to differences in outcome after specific cancer treatment such as HDCT/ASCT.

VDR-signaled effects may modulate cell differentiation in various stages of hematopoiesis. VitD analogues have been shown to promote apoptosis and cell cycle arrest in myeloma cells. ${ }^{41-43}$ Furthermore, inhibition of proliferation in lymphoma cell lines was achieved following VitD supplementation in murine models. ${ }^{44}$ In summary, patients with normal VitD levels may benefit from these VDR-mediated mechanisms at various stages of the course of their disease. With regards to eventual therapeutic intervention, there is an ongoing debate on how much VitD is required to exert its effects on cell differentiation and immune modulation. It has also been suggested that these levels may range in supra-physiologic concentrations to generate immune responses, causing at the same time relevant complications such as hypercalcemia. ${ }^{7,9,10}$ Furthermore, low VitD serum levels in principle could identify specific risk 
groups in patients with hematological or solid malignancies, and the supplemental correction of reduced VitD serum levels does not necessarily compensate the apparent adverse prognostic association of low VitD levels in these patients.

This study analyzed a patient cohort undergoing HDCT with ASCT between 2012 and 2018. Despite the obvious limitations of a retrospective study covering such a long period, considerable heterogeneity concerning disease subtypes, pretreatment, remission status, type of HDCT, and subsequent treatment after ASCT, we identified a significant association of VitD levels $>52 \mathrm{nmol} / \mathrm{L}$ at the time of HDCT with ASCT with superior outcomes. This association was most evident in the myeloma patients but was documented as well in the patients with lymphomas. Consequently, it is tempting to recommend correcting low VitD levels at HDCT/ASCT, particularly since this is a rather inexpensive and easy intervention with a favorable toxicity profile. Prospective interventional studies should be initiated to explore the efficacy of such strategy in a larger, randomized, and prospective setting.

Conflict of interest: The authors declare no conflict of interest.

Contributions: FE: performed research and wrote the paper; BMT, CS: contributed vital data; UB: analyzed data and wrote the paper; TP: designed research, analyzed data and wrote the paper. All authors were involved in drafting the manuscript, and all authors read and approved the final version.

Funding: No funding was received for this study.

Acknowledgements: The authors wish to thank the data management, the apheresis, the flow cytometry and the stem cell laboratory teams of the ASCT program at the University hospital of Bern and its associated partner hospitals and collaborators for documentation of data relevant for this study. 


\section{References}

[1] Majhail NS, Farnia SH, Carpenter PA, et al. Indications for Autologous and Allogeneic Hematopoietic Cell Transplantation: Guidelines from the American Society for Blood and Marrow Transplantation. Biol Blood Marrow Transplant 2015;21:1863-1869.

[2] Kelta M, Zekri J, Abdelghany E, et al. High-dose chemotherapy and peripheral hematopoietic stem cell transplantation in relapsed/refractory hodgkin's lymphoma. Tumori 2018:104;471-475.

[3] Kondo E. Autologous Hematopoietic Stem Cell Transplantation for Diffuse Large B-Cell Lymphome. J Clin Exp Hematop 2016:56;100-108.

[4] Hall AC, Juckett MB. The role of vitamin D in hematologic disease and stem cell transplantation. Nutrients 2013;5:2206-2221.

[5] Caballero-Velazquez T, Montero I, Sanchez-Guijo F, et al. Immunomodulatory Effect of Vitamin D after Allogeneic Stem Cell Transplantation: Results of a Prospective Multicenter Clinical Trial. Clin Cancer Res 2016;22:5673-5681.

[6] Ros-Soto J, Anthias C, Madrigal A, et al. Vitamin D: is it important in haemopoietic stem cell transplantation? A review. Bone Marrow Transplant 2019;54:810-820.

[7] Bunce CM, Brown G, Hewison M. Vitamin D and hematopoiesis. Trends Endocrinol Metab 1997;8:245-251.

[8] Luong QT, Koeffler HP. Vitamin D compounds in leukemia. J Steroid Biochem Mol Biol 2005;97:195-202.

[9] Baeke F, Takiishi, Korf H, et al. Vitamin D: modulator of the immune system. Curr Opin Pharmacol 2010;10:482-496.

[10] Hewison M. An update on vitamin D and human immunity. Clin Endocrinol (Oxf) 2012;76:315-325.

[11] Bikle DD. Vitamin D metabolism, mechanism of action, and clinical applications. Chem Biol. 2014;21:319-329.

[12] Hilger J, Friedel A, Herr R, et al. A systematic review of vitamin D status in populations worldwide. Br J Nutr 2014:111;23-45. 
[13] Raduikovic A, Kordelas L, Krzykalla J, et al. Pretransplant vitamin D deficiency Is associated with higher relapse rates in patients allografted for myeloid malignancies. $\mathrm{J}$ Clin Oncol 2017;35:3143-3152.

[14] Joseph RW, Alousi A, Konda B, et al. High incidence of vitamin D deficiency in patients undergoing allogeneic stem cell transplantation. Am J Hematol 2011;86:954-6.

[15] Thomas X, Chelghoum Y, Fanari N, et al. Serum 25-hydroxyvitamin D levels are associated with prognosis in hematological malignancies. Hematology 2011:16;278283.

[16] Lee $\mathrm{HJ}$, Muindi JR, Tan W, et al. Low 25(OH) vitamin D3 levels are associated with adverse outcome in newly diagnosed, intensively treated adult acute myeloid leukemia. Cancer 2014;120:521-529.

[17] Borchmann S, Cirillo M, Goergen H, et al. Pretreatment Vitamin D Deficiency Is Associated With Impaired Progression-Free and Overall Survival in Hodgkin Lymphoma. J Clin Oncol 2019:37;3528-3537.

[18] Ma Y, Zhang P, Wang F, et al. Association between vitamin D and risk of colorectal cancer: a systematic review of prospective studies. J Clin Oncol 2011:29;3775-3782.

[19] Li M, Chen P, Li J, et al. Review: the impacts of circulating 25-hydroxyvitamin D levels on cancer patient outcomes: a systematic review and meta-analysis. J Clin Endocrinol Metab 2014:99;2327-2336.

[20] Mezawa $H$, Sugiura $T$, Watanabe $M$, et al. Serum vitamin D levels and survival of patients with colorectal cancer: post-hoc analysis of a prospective cohort study. BMC Cancer 2010:10;347-352.

[21] Hsu JY, Feldman D, McNeal JE, et al. Reduced 1alpha-hydroxylase activity in human prostate cancer cells correlates with decreased susceptibility to 25-hydroxyvitamin D3induced growth inhibition. Cancer Res 2001:61;2852-2856.

[22] Tretli S, Hernes E, Berg JP, et al. Association between serum 25(OH)D and death from prostate cancer. Br J Cancer 2009:100;450-454.

[23] Grant WB: Relation between prediagnostic serum 25-hydroxyvitamin D level and incidence of breast, colorectal, and other cancers. J Photochem Photobiol B. 2010:101;130-136. 
[24] Kim HJ, Lee YM, Ko BS, et al. Vitamin D deficiency is correlated with poor outcomes in patients with luminal-type breast cancer. Ann Surg Oncol 2011:18;1830-1836.

[25] Tretli S, Schwartz GG, Torjesen PA, et al. Serum levels of 25-hydroxyvitamin D and survival in Norwegian patients with cancer of breast, colon, lung, and lymphoma: a population-based study. Cancer Causes Control 2012:23;363-370.

[26] Amaral AF, Méndez-Pertuz M, Muñoz A, et al: Plasma 25-hydroxyvitamin D(3) and bladder cancer risk according to tumor stage and FGFR3 status: a mechanism-based epidemiological study. J Natl Cancer Inst 2012:104;1897-1904.

[27] Yin L, Grandi N, Raum E, et al. Meta-analysis: Circulating vitamin D and ovarian cancer risk. Gynecol Oncol 2011:121;369-375.

[28] Mohapatra S, Saxena A, Gandhi G, et al. Vitamin D and VDR gene polymorphism (Fokl) in epithelial ovarian cancer in Indian population. J Ovarian Res 2013:6;37-44.

[29] Liu Y, Chen W, Hu ZB, et al. Plasma Vitamin D Levels And Vitamin D Receptor Polymorphisms Are Associated with Survival of Non-small Cell Lung Cancer. Chin J Cancer Res 2011:23;33-37.

[30] Zhou W, Heist RS, Liu G, et al. Circulating 25-hydroxyvitamin D levels predict survival in early-stage non-small-cell lung cancer patients. J Clin Oncol 2007:25;479-485.

[31] Roskies M, Dolev Y, Caglar D, et al. Vitamin D deficiency as a potentially modifiable risk factor for thyroid cancer. J Otolaryngol Head Neck Surg 2012:41;160-163.

[32] Li M, Chen P, Li J, et al. Review: the impacts of circulating 25-hydroxyvitamin D levels on cancer patient outcomes: A systematic review and meta-analysis. J Clin Endocrinol Metab 2014;99:2327-2336.

[33] Drake MT, Maurer MJ, Link BK, et al. Vitamin D insufficiency and prognosis in nonHodgkin's lymphoma. J Clin Oncol 2010;28:4191-4198.

[34] Shanafelt TD, Drake MT, Maurer MJ, et al. Vitamin D insufficiency and prognosis in chronic lymphocytic leukemia. Blood 2011;117:1492-1498.

[35] Wang W, Li G, He X, et al. Serum 25-hydroxyvitamin D levels and prognosis in hematological malignancies: a systematic review and meta-analysis. Cell Physiol Biochem 2015:35;1999-2005. 
[36] Raoufinejad K, Shamshiri AR, Pezeshki S, et al. Oral calcitriol in hematopoietic recovery and survival after autologous stem cell transplantation: a randomized clinical trial. Daru 2019:27;709-720.

[37] Holick MF, Binkley NC, Bischoff-Ferrari HA, et al. Evaluation, treatment, and prevention of vitamin $D$ deficiency: an Endocrine Society clinical practice guideline. J Clin Endocrinol Metab 2011;96:1911-1930.

[38] Melamed ML, Michos ED, Post W, et al. 25-hydroxyvitamin D levels and the risk of mortality in the general population. Arch Intern Med 2008;168:1629-1637.

[39] Medrano M, Carrillo-Cruz E, Montero I, et al. Vitamin D: Effect on Haematopoiesis and Immune System and Clinical Applications. Int J Mol Sci 2018;19:2663.

[40] Arain A, Matthiesen C: Vitamin D deficiency and graft-versus-host disease in hematopoietic stem cell transplant population. Hematol Oncol Stem Cell Ther 2019;12:133-139.

[41] Kumagai T, O'Kelly J, Said JW, et al. Vitamin D2 analog 19-nor-1,25-dihydroxyvitamin D2: antitumor activity against leukemia, myeloma, and colon cancer cells. J Natl Cancer Inst 2003;95:896-905.

[42] Park WH, Seol JG, Kim ES, et al. Cell cycle arrest induced by the vitamin D(3) analog EB1089 in NCl-H929 myeloma cells is associated with induction of the cyclindependent kinase inhibitor p27. Exp Cell Res 2000;254:279-286.

[43] Park WH, Seol JG, Kim ES, et at. The induction of apoptosis by combined 1,25(OH)2D3 analog, EB1089 and TGF $\beta 1$ in $\mathrm{NCl}-\mathrm{H} 929$ multiple myeloma cells. Int $\mathrm{J}$ Oncol 2002:20;533-542.

[44] Hickish T, Cunningham D, Colston K, et al. The effect of 1,25-dihydroxyvitamin D3 on lymphoma cell lines and expression of the vitamin $\mathrm{D}$ receptor in lymphoma. $\mathrm{Br} \mathrm{J}$ Cancer 1993:68;668-672.

[45] Ross AC, Taylor CL, Yaktine AL, et al. Institute of Medicine (US) Committee to Review Dietary Reference Intakes for Vitamin D and Calcium. Washington, DC: The National Academies Press 2011;1:94-98. 


\section{Tables}

Table 1: Comparison of clinical characteristics at diagnosis in 183 patients undergoing HDCT/ ASCT with $25-\mathrm{OH}-\mathrm{D}$ levels above versus below $52 \mathrm{nmol} / \mathrm{L}$.

\begin{tabular}{|c|c|c|c|c|c|}
\hline \multicolumn{3}{|c|}{ Parameter } & \multicolumn{2}{|c|}{ 25-OH-D serum level } & \multirow[b]{2}{*}{$\mathbf{p}$} \\
\hline & & & $>52 \mathrm{nmol} / \mathrm{L}$ & $\leq 52 \mathrm{nmol} / \mathrm{L}$ & \\
\hline \multicolumn{3}{|c|}{ Number of patients (\%) } & $81(44)$ & $102(56)$ & - \\
\hline \multicolumn{3}{|c|}{ Males/females (ratio) } & $50 / 31(1.6)$ & $78 / 24(3.2)$ & 0.0356 \\
\hline \multicolumn{3}{|c|}{ 25-OH-D, nmol/L, median (range) } & $68(53-123)$ & $35^{1}(<12-52)$ & - \\
\hline \multicolumn{3}{|c|}{ Age at ASCT, median (range) } & $61(24-74)$ & $60(25-77)$ & 0.5555 \\
\hline \multicolumn{3}{|c|}{ Body weight at ASCT, $\mathrm{kg}$, median (range) } & $70(43-116)$ & $77(46-122)$ & 0.0098 \\
\hline \multicolumn{3}{|c|}{ Multiple myeloma $(n=104) \quad n(\%)$} & $42(100)$ & $62(100)$ & - \\
\hline \multirow[t]{3}{*}{ ISS $^{1}$} & 1 & n (\%) & $21(50)$ & $20(32)$ & 0.1014 \\
\hline & II & $\mathrm{n}(\%)$ & $13(31)$ & $23(37)$ & 0.5374 \\
\hline & III & n (\%) & $8(19)$ & $19(31)$ & 0.2549 \\
\hline & $\begin{array}{l}\text { n (\%) } \\
\text { n (\%) }\end{array}$ & $\begin{array}{c}0 \\
39(100)\end{array}$ & $\begin{array}{c}1 \\
39(100)\end{array}$ & $\begin{array}{l}- \\
-\end{array}$ \\
\hline \multicolumn{2}{|c|}{$\begin{array}{c}\text { NHL }(\boldsymbol{n}=\mathbf{7 8}) \\
\text { DLBCL }\end{array}$} & n (\%) & $18(46)$ & $21(54)$ & 0.6509 \\
\hline \multirow{2}{*}{\multicolumn{2}{|c|}{$\begin{array}{l}\mathrm{MCL} \\
\mathrm{FCL}\end{array}$}} & n (\%) & $5(13)$ & $3(8)$ & 0.7115 \\
\hline & & n (\%) & $3(8)$ & $4(10)$ & 0.9999 \\
\hline \multicolumn{2}{|c|}{$\begin{array}{l}\mathrm{FCL} \\
\mathrm{CNSL}\end{array}$} & n (\%) & $5(13)$ & $1(3)$ & 0.2002 \\
\hline & $\mathrm{n}(\%)$ & $4(10)$ & $4(10)$ & 0.9999 \\
\hline & Others & n (\%) & $4(10)$ & $6(15)$ & 0.7366 \\
\hline \multirow[t]{6}{*}{ Stage } & 1 & $\mathrm{n}(\%)$ & $2(5)$ & $2(5)$ & 0.9999 \\
\hline & II & n (\%) & $3(8)$ & $3(7)$ & 0.9999 \\
\hline & III & n (\%) & 7 (18) & $5(13)$ & 0.5458 \\
\hline & IV & n (\%) & $17(44)$ & $22(55)$ & 0.3711 \\
\hline & unknown & n (\%) & $10(26)$ & $8(20)$ & 0.6001 \\
\hline & B symptoms² & n (\%) & $12(41)$ & $13(41)$ & 0.9999 \\
\hline \multirow[t]{5}{*}{ IPI } & $0-1$ & n (\%) & $7(18)$ & $4(10)$ & 0.3482 \\
\hline & 2 & $\mathrm{n}(\%)$ & $5(13)$ & $7(17)$ & 0.7555 \\
\hline & 3 & n (\%) & 7 (18) & $11(28)$ & 0.4255 \\
\hline & $4-5$ & $\mathrm{n}(\%)$ & $11(28)$ & $8(20)$ & 0.4391 \\
\hline & unknown & n (\%) & $9(23)$ & $10(25)$ & 0.9999 \\
\hline \multicolumn{3}{|c|}{ Remission status at ASCT } & & & \\
\hline & $\mathrm{CR}$ & $\mathrm{n}(\%)$ & $13(16)$ & $23(23)$ & 0.3497 \\
\hline & VGPR & $\mathrm{n}(\%)$ & $16(20)$ & $19(19)$ & 0.8523 \\
\hline & PR & $\mathrm{n}(\%)$ & $45(56)$ & $39(38)$ & 0.0250 \\
\hline & SD & $\mathrm{n}(\%)$ & $4(5)$ & $5(5)$ & 0.9999 \\
\hline & PD & $\mathrm{n}(\%)$ & $3(4)$ & $16(16)$ & 0.0129 \\
\hline
\end{tabular}

"Exact Fisher's test" and "unpaired t-test" were applied to calculate p-values. Abbreviations: 25-OH-D: 25hydroxyvitamine D serum level; (R-ISS): (Revised) Multiple Myeloma International Staging System; NHL: NonHodgkin lymphoma; DLBCL: diffuse large B-cell lymphoma; MCL: mantle cell lymphoma; FCL: follicle center lymphoma; CNSL: central nervous system lymphoma; TCL: T-cell lymphoma; IPI: International Prognostic Index; CR: complete remission; VGPR: very good partial remission; PR: partial remission; SD: stable disease; PD: progressive disease. ${ }^{1} 6$ patients staged by R-ISS instead of ISS. ${ }^{2}$ Percentage values of B symptoms refer to the total of stage I, II, III and IV. 
Table 2: Clinical characteristics of patients with 25-OH-D levels above versus below $52 \mathrm{nmol} / \mathrm{L}$ determined at the time of HDCT/ASCT.

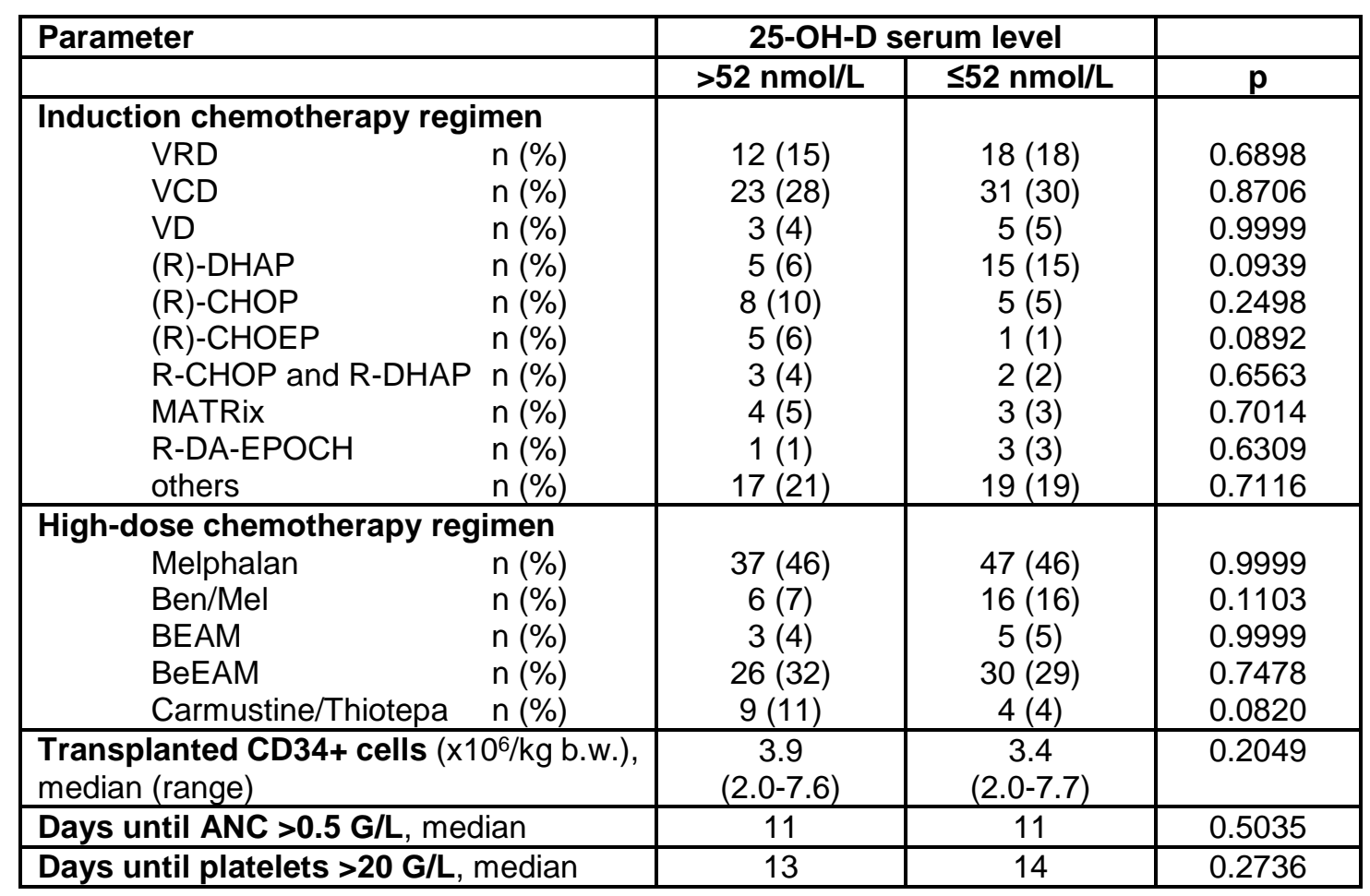

Exact Fisher's test and unpaired t-test were applied to calculate p-values. VRD: velcade (bortezomib), revlimid (lenalidomide), dexamethasone; VCD: bortezomib, cytarabine, dexamethasone; VD: bortezomib, dexamethasone; (R-)DHAP: rituximab, dexamethasone, high-dose cytarabine, cisplatin; (R-)CHOP: rituximab, cyclophosphamide, oncovin (vincristin), predniso(lo)ne; (R-)CHOEP: + etoposide; MATRix: methotrexate, cytarabine, thiotepa, rituximab; R-DA-EPOCH: dose-adjusted rituximab, etoposide, prednisolone, oncovin, cyclophosphamide, hydroxydaunorubicin; Ben/Mel: bendamustine, melphalan; BEAM: carmustine, etoposide, cytarabine, melphalan; BeEAM: bendamustine, etoposide, cytarabine, melphalan; b.w.: body weight; ANC: absolute neutrophil count. 
Table 3: Multivariable analysis of overall survival to evaluate the prognostic relevance of various predictors.

\begin{tabular}{|l|c|c|c|c|}
\hline \multirow{2}{*}{ Parameter } & \multicolumn{2}{|c|}{ Overall survival $^{\mathbf{1}}$} & \multicolumn{2}{c|}{ Overall survival $^{\mathbf{2}}$} \\
\cline { 2 - 5 } & $\begin{array}{c}\text { Hazard ratio } \\
\mathbf{9 5 \%} \mathbf{~ C l )}\end{array}$ & $\mathbf{p}$ & $\begin{array}{c}\text { Hazard ratio } \\
\mathbf{( 9 5 \%} \mathbf{~ C l})\end{array}$ & $\mathbf{p}$ \\
\hline Gender (male vs. female) & $1.37(0.66-2.94)$ & 0.4041 & $1.55(0.74-3.33)$ & 0.239 \\
\hline Category (myeloma vs. lymphoma) & $0.59(0.30-1.18)$ & 0.1349 & $0.64(0.3-1.24)$ & 0.171 \\
\hline Age & $1.01(0.97-1.07)$ & 0.4007 & $1.01(0.97-1.06)$ & 0.8902 \\
\hline Remission (CR/VGPR vs. PR/SD/PD) & $0.87(0.42-1.88)$ & 0.6980 & $0.67(0.36-1.38)$ & 0.294 \\
\hline 25-OH-D level & $0.98(0.97-1.00)$ & 0.0167 & $0.51(0.26-0.98)$ & 0.0421 \\
\hline
\end{tabular}

${ }^{1}$ Multivariable cox regression with OS as a dependent variable and vitamin $D$ as a continuous independent variable. ${ }^{2}$ Multivariable cox regression with OS as a dependent variable and patients stratified in two groups according to the median vitamin D serum level (>52 vs. $\leq 52 \mathrm{nmol} / \mathrm{L}$ ). Cl: confidence interval; CR: complete remission; VGPR: very good partial remission; PR: partial remission; SD: stable disease; PD: progressive disease. 
Figure 1:
A) PFS all patients
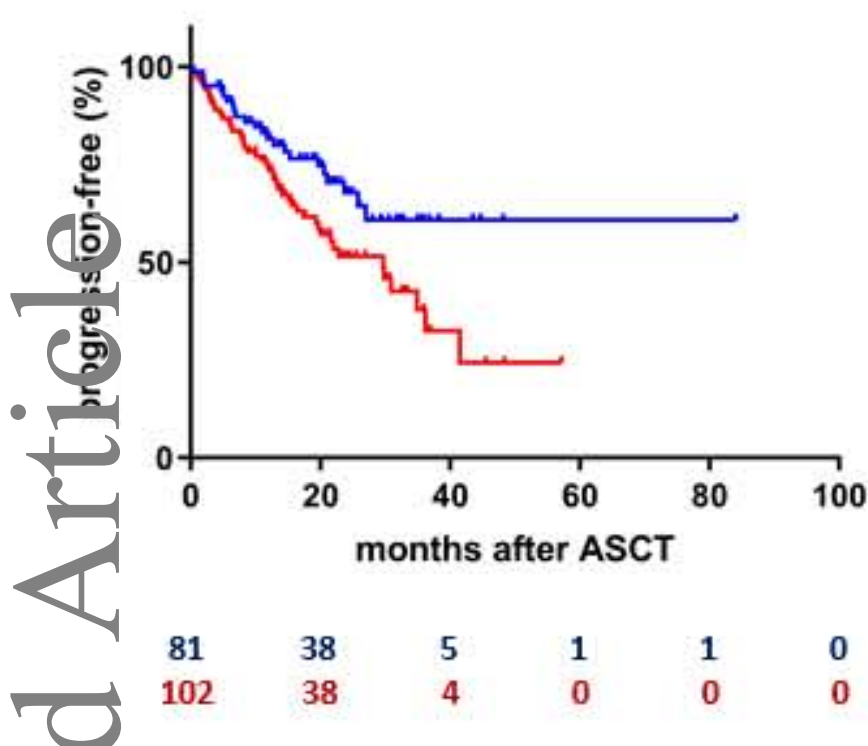

4

(1)

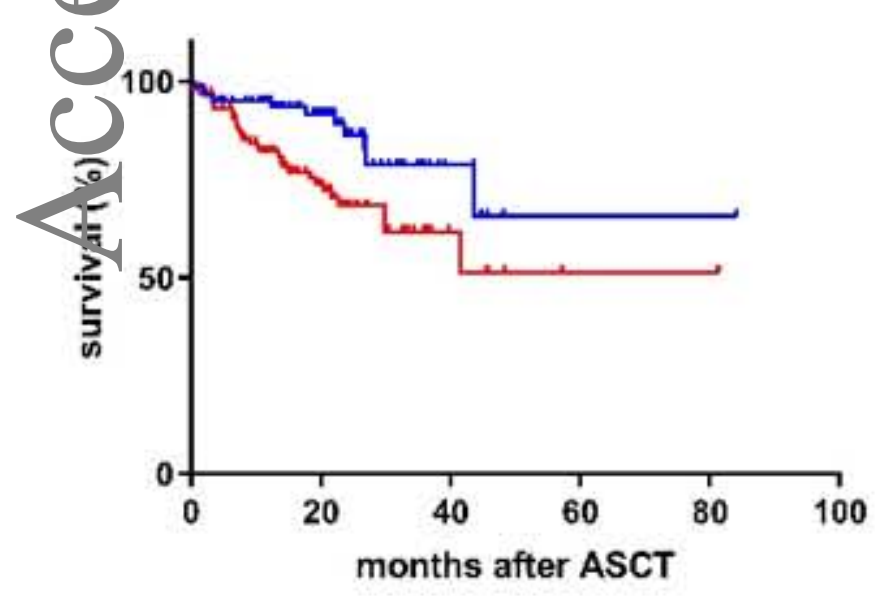

$\begin{array}{cccccc}81 & 46 & 7 & 1 & 1 & 0 \\ 102 & 47 & 6 & 1 & 1 & 0\end{array}$

\section{[o] os all patients}

\section{B) PFS lymphoma patients}

$-25-\mathrm{OH}-\mathrm{D} 3>52$

$-25-\mathrm{OH}-\mathrm{D} 3<52$ $\mathrm{p}=\mathbf{0 . 0 1 9 4}$

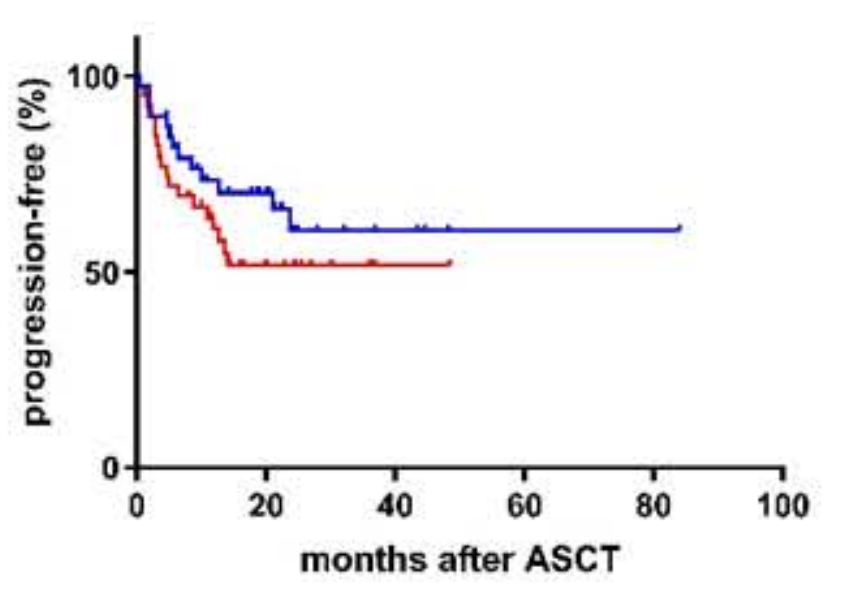

- $25-\mathrm{OH}-\mathrm{D} 3>52$

$-25-\mathrm{OH}-\mathrm{D} 3<52$ $p=0.251$
C) PFS myeloma patients

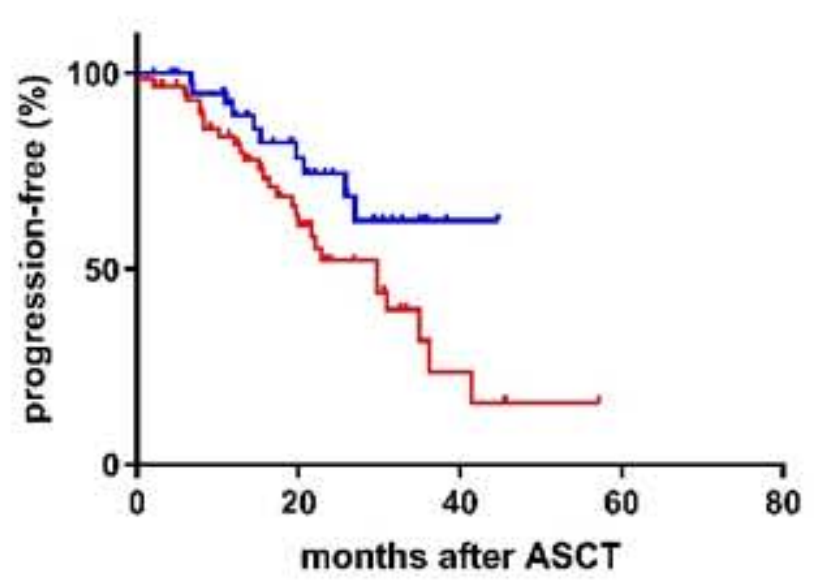

$\begin{array}{ll}42 & 21 \\ 62 & 26\end{array}$

F) OS myeloma patients

- 25-OH-D3 $>52$

- $25-\mathrm{OH}-\mathrm{D} 3<52$ $p=0.011$

\section{E) OS lymphoma patients}

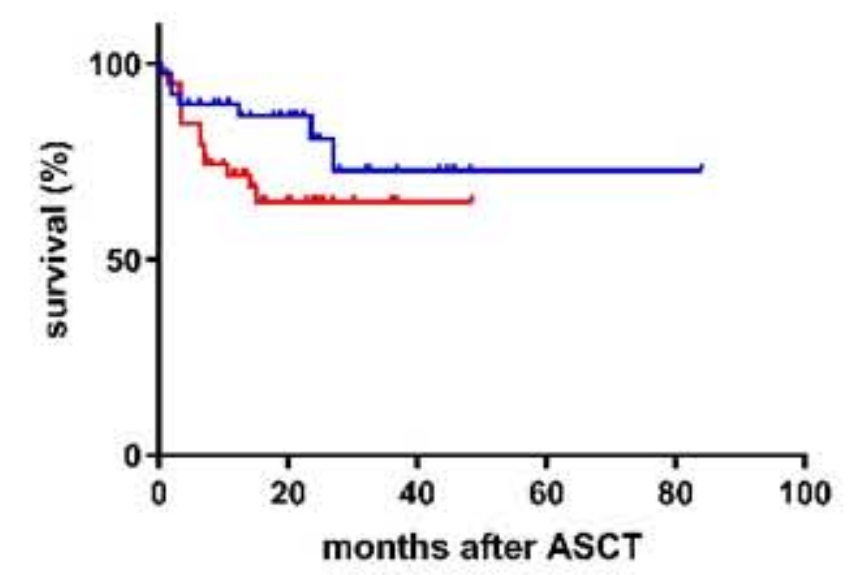

- $25-\mathrm{OH}-\mathrm{D} 3>52$

$-25-\mathrm{OH}-\mathrm{D} 3<52$ $p=0.1242$

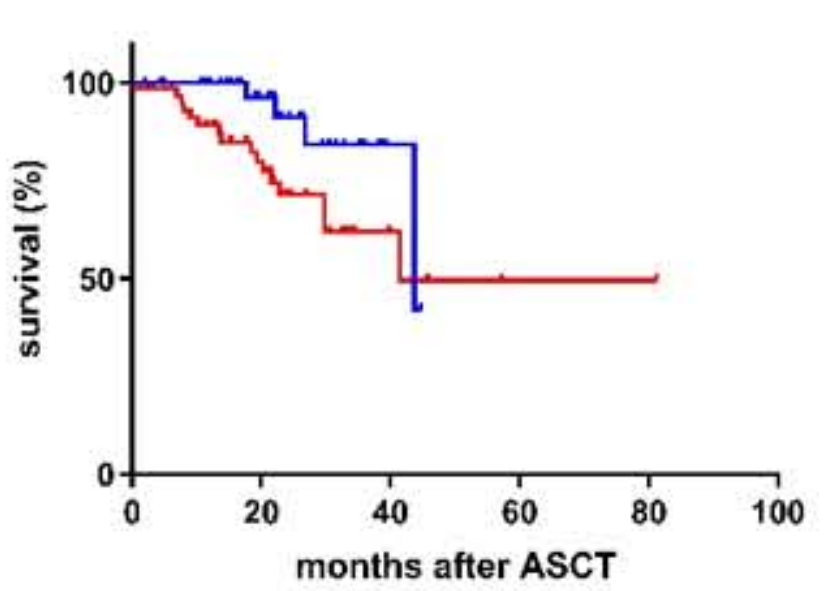

$\begin{array}{llllll}42 & 24 & 3 & 0 & 0 & 0\end{array}$
- 25-OH-D3 $>52$

- 25-OH-D3 $<52$ $p=0.0412$
- $25-\mathrm{OH}-\mathrm{D} 3>52$

$-25-\mathrm{OH}-\mathrm{D} 3<52$ $p=0.049$ 